\title{
Scholarship in Extended Curriculum Programmes
}

\author{
Vivienne Bozalek \\ https://orcid.org/0000-0002-3212-1910 \\ Rhodes University, South Africa \\ vbozalek@gmail.com
}

\author{
Aditi Hunma \\ https://orcid.org/0000-0001-7714-2996 \\ University of Cape Town, South Africa \\ Aditi.Hunma@uct.ac.za
}

There is a paucity of academic studies from the Extended Curriculum Programmes (ECPs) in South African universities, with scholarly writings in this sector just beginning to burgeon. This dearth can be ascribed to the increasing casualisation and precarity experienced by academics employed in these programmes. Academics in this sector are overburdened with teaching loads, and they often do not have access to research funds. Moreover, those in this sector, especially emerging scholars, are often excluded from the processes and knowledge of how to set about becoming active and engaged writing participants in academia. It is only at a few institutions that ECP academics receive mentorship to pursue further postgraduate qualifications and to develop themselves as educators.

Underpinning our Call for Papers, we stated our understanding of scholarship to mean that it should incorporate a number of different processes including the research interests of the academic teaching staff into curriculum content; that students are taught the processes of research rather than focus solely on content; that the curriculum would be enquiry-based; and, that academics would be involved in researching their own pedagogical practice. We hope that these underpinnings resonate in the selection of articles published in the journal.

For this Themed Section or Special Issue of Education as Change, we invited emerging and established scholars to participate in an exploration about scholarship in the Extended Curriculum. The rich and textured contributions we received are testimony to a growing scholarly interest in the theoretical underpinnings and practical implementation of these programmes at universities. These contributions cover a range of disciplinary fields, including the teaching of physics, art history, and design, as well as academic practices such as assessment, arts-based pedagogies, "slow scholarship" and new materialism, African feminist research projects, enquiry-based learning, and multimodality.

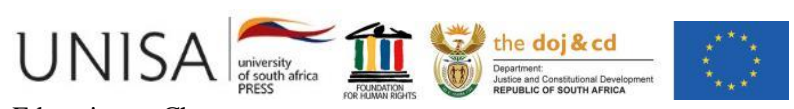

Education as Change

https://unisapressjournals.co.za/index.php/EAC

Volume 25 | 2021 |\#10458 | 2 pages

https://doi.org/10.25159/1947-9417/10458 ISSN 1947-9417 (Online)

(C) The Author(s) 2021 
We would like to thank the writers, Delia Marshall, Amalia Beagle, Corinne Knowles, Amanda Morris, Nike Romano, Anita Jonker, Pragashni Padayachee, Anita Campbell and Precious Mudavanhu, Arlene Archer and Christine Price, Gideon Nomdo and Sean Samson, for their submissions. We would also like to thank the anonymous reviewers for their comments and critiques of often difficult texts.

One of the contributors to this Themed Section, Alwyn Louw, passed away after he had submitted his abstract. His passing meant that we were not able to engage him in the peer-review process, and we are bound by the review ethics of academic publishing not to publish his article. We would like to acknowledge him and the work he did for the scholarship of teaching and learning in the extended curriculum at Stellenbosch University. 